\title{
Back-to-Back Comparison of Auto-Fluorescence Imaging (AFI) Versus High Resolution White Light Colonoscopy for Adenoma Detection
}

\author{
Kentaro Moriichi ${ }^{1}$, Mikihiro Fujiya ${ }^{1 *}$, Ryu Sato ${ }^{2,3}$, Jiro Watari ${ }^{3,4}$, Yoshiki Nomura ${ }^{1}$, Toshie Nata ${ }^{1}$, Nobuhiro Ueno ${ }^{1}$, \\ Shigeaki Maeda ${ }^{3}$, Shin Kashima ${ }^{1,3}$, Kentaro Itabashi', Chisato Ishikawa', Yuhei Inaba', Takahiro Ito', \\ Kotaro Okamoto ${ }^{1}$, Hiroki Tanabe ${ }^{1}$, Yusuke Mizukami ${ }^{1}$, Yusuke Saitoh ${ }^{5}$ and Yutaka Kohgo ${ }^{1}$
}

\begin{abstract}
Background: Some patients under close colonoscopic surveillance still develop colorectal cancer, thus suggesting the overlook of colorectal adenoma by endoscopists. AFI detects colorectal adenoma as a clear magenta, therefore the efficacy of AFI is expected to improve the detection ability of colorectal adenoma. The aim of this study is to determine the efficacy of $\mathrm{AFI}$ in detecting colorectal adenoma.
\end{abstract}

Methods: This study enrolled 88 patients who underwent colonoscopy at Asahikawa Medical University and Kushiro Medical Association Hospital. A randomly selected colonoscopist first observed the sigmoid colon and rectum with conventional high resolution endosopy (HRE). Then the colonoscopist changed the mode to AFI and handed to the scope to another colonoscopist who knew no information about the HRE. Then the second colonoscopist observed the sigmoid colon and rectum. Each colonoscopist separately recorded the findings. The detection rate, miss rate and procedural time were assessed in prospective manner.

Results: The detection rate of flat and depressed adenoma, but not elevated adenoma, by AFI is significantly higher than that by HRE. In less-experienced endoscopists, AFI dramatically increased the detection rate (30.3\%) and reduced miss rate (0\%) of colorectal adenoma in comparison to those of HRE $(7.7 \%, 50.0 \%)$, but not for experienced endoscopists. The procedural time of HRE was significantly shorter than that of AFI.

Conclusions: AFI increased the detection rate and reduced the miss rate of flat and depressed adenomas. These advantages of AFI were limited to less-experienced endoscopists because experienced endoscopists exhibited a substantially high detection rate for colorectal adenoma with HRE.

Keywords: Autofluorescence imaging, Colorectal adenoma, Detection rate, Flat and depressed adenoma, Less-experienced endoscopist, High-resolution colonoscope

\section{Background}

Colorectal cancer is one of the most common malignant tumors in Eastern and Western countries [1]. During the process of colon carcinogenesis, normal epithelia are thought to initially turn into benign adenomas, accumulate gene alterations and then transform to advanced adenocarcinomas [2] [3]. All adenoma are considered to

\footnotetext{
* Correspondence: fjym@asahikawa-med.ac.jp

'Division of Gastroenterology and Hematology/Oncology, Department of Medicine, Asahikawa Medical University, 2-1 Midorigaoka-higashi, Asahikawa, Hokkaido 078-8510, Japan

Full list of author information is available at the end of the article
}

be premalignant lesions. The elimination of colon adenoma is therefore an effective strategy to prevent the development of colon cancer. Several trials on an endoscopic resection for colon adenoma successfully decreased the mortality of colon cancer [4]. However, some patients under close colonoscopic surveillance still develop colorectal cancer [5]. This discrepancy may be caused by the rapid progression of adenomas as well as the overlooking of colorectal adenoma. Indeed, systematic reviews of backto back colonoscopies showed that $15 \%$ to $32 \%$ of colorectal adenomas were possibly missed by colonoscopy [6], particularly flat and depressed adenomas [7] [8] [9] [10]. 
Advanced endoscopic instruments may therefore decrease the miss rate of adenomas and optimize the potential for colorectal cancer prevention.

AFI is a novel technology which can capture fluorescence $(500-630 \mathrm{~nm})$ emitted from intestinal or other tissues. This device produces an excitation light source of $442 \mathrm{~nm}$, delivers it to the tissue surface and then captures the reflection and fluorescence by two high-sensitivity CCDs. Those captured signals are respectively transformed into red or blue colors, and then are displayed on the monitor as a color image in real-time [11] [12]. Fluorescence imaging is thought to be an efficient tool for the evaluation of dysplasia in Barrett esophagus [13] [14] [15], esophageal and gastric cancer [16] and dysplasia [17] [18] [19], as well as for making a differential diagnosis of intestinal lymphoma [20] and also for assessing the inflammation activity in ulcerative colitis [21]. Three studies proposed the controversial results concerning the usefulness of AFI on the detection of colon lesions. Matsuda et al. proposed the predominance of AFI for detecting polyps of the proximal colon compared to white light endoscopy using a modified back-to-back method [22]. In contrast, the other two studies showed that AFI did not reduce the adenoma miss-rate using two inspections of the entire colon by conventional high-resolution endoscopy (HRE) or AFI [23] [24]. There seems to be some bias with regard to these results, since the endoscopic findings of HRE and AFI could not be assessed independently because each colonoscopic examination was performed by a single endoscopist in those studies. Therefore, the efficacy of AFI in detecting colorectal adenoma still remains to be elucidated.

The current study aimed to assess the efficacy of AFI for improving the colorectal adenoma detection rate by comparing experienced and less experienced endoscopists in a prospective manner.

\section{Methods}

\section{Patients}

This prospective study was registered with University Hospital Medical Information Network (ID number; R000002463). Written informed consent was obtained from all patients enrolled and the study was approved by the institutional review board of Asahikawa Medical University and Kushiro Medical Association Hospital. Eightyeight patients were enrolled in this prospective study. All patients underwent colonoscopy with an AFI examination (CF-FH260AZI, Olympus medical systems, Tokyo, Japan) at Asahikawa Medical University and Kushiro Medical Association Hospital between January 2008 and December 2008. According to the inclusion criteria, patients who could understand the background information, aims, methods and potential adverse effects of participating in the study were enrolled. The exclusion criteria were an age younger than 18 years, polyposis syndrome, inflammatory bowel disease, severe coagulopathy, stricture, bleeding, and severe cardiac, pulmonary or renal diseases. A total of 193 patients were initially eligible for this study, and 108 of these patients were excluded because they did not consent to participate. Finally, 88 patients were

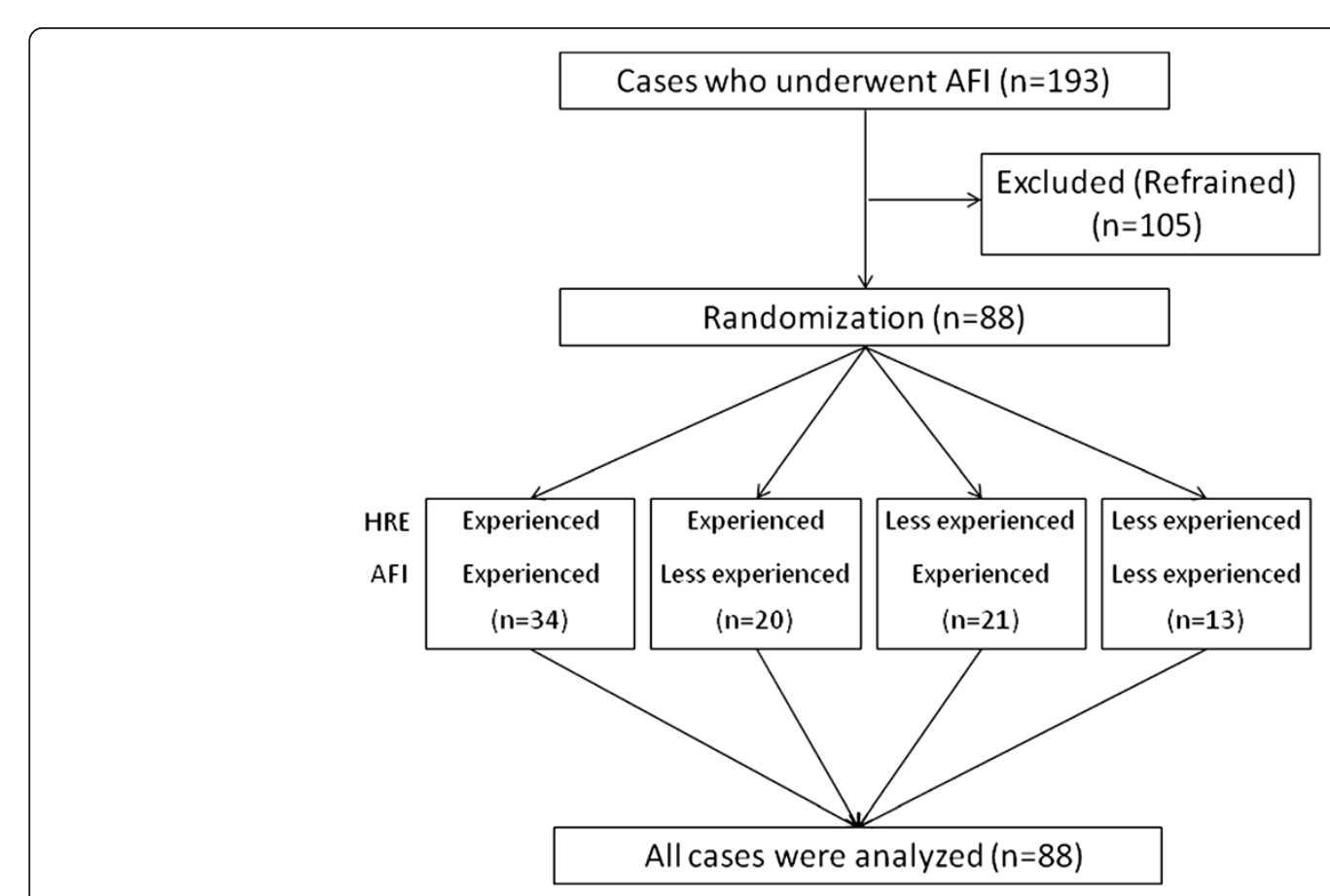

Figure $1 \mathrm{~A}$ flow diagram of this study. 
enrolled in this study (Figure 1). The demographics of the enrolled patients and detected lesions are summarized in Table 1. The indications for colonoscopy were abdominal symptoms such as abdominal pain and abnormal defecation in 28 patients, for screening in 38 patients and for surveillance in 22 patients. The shape of the lesions was classified according to the Paris endoscopic classification [25].

\section{Colonoscopic instruments}

A high definition colonoscope (CF-FH260AZI; Olympus Inc.) containing 2 CCDs: 1 for HRE/NBI and 1 for AFI, an Olympus Lucera Spectrum video processor and a high definition monitor were used for the colonoscopy studies. AFI uses blue light $(390-470 \mathrm{~nm})$ for excitation and green light (540-560 $\mathrm{nm}$ ) is for reflection. A barrier filter allows passage of light to the charge-coupled devices with wavelengths between 500 and $630 \mathrm{~nm}$ only, and consisting of autofluorescence emission and green reflectance. AFI images were diagnosed based on the predominant color intensity. The normal mucosa and adenoma appear green and magenta, respectively, by AFI (Figure 2).

\section{Colonoscopic procedure and randomization}

All patients were prepared using $2 \mathrm{~L}$ of polyethylene glycol solution in this study. None of them exhibited insufficient bowel preparation. All procedures were performed by one of either 5 experienced endoscopists ( $>8000$ standard and $>100$ AFI) or 3 less-experienced endoscopists $(<500$ standard and $<10 \mathrm{AFI})$. Because this study aimed to elucidate the differences in the significance of AFI between experienced and lessexperienced endoscopists, we selected highly experienced endoscopists and endoscopists with much less

\begin{tabular}{lc} 
Table 1 Demographics of the patients and detected \\
lesions \\
\hline M : F & $45: 43$ \\
Mean age (y.o.) & $64.0 \pm 10.0$ \\
Indication for colonoscopy & $28: 38: 22$ \\
Indication for colonoscopy (symptoms: screening: & \\
surveillance) & 88 \\
Number of lesions & 29 \\
Adenoma & $5.8 \pm 6.5$ \\
Size (mm) & 18 \\
Type 0-Ila & 11 \\
Type 0-llb or 0-Ilc & 59 \\
Hyperplasia & $3.7 \pm 1.8$ \\
Size (mm) & 13 \\
Elevated & 46 \\
Flat \& depressed & \\
\hline
\end{tabular}

experience. A colonoscopist who was randomly selected with a sealed envelope method first observed the sigmoid colon and rectum (for $40 \mathrm{~cm}$ from anal verge) with HRE. Next, the colonoscopist changed the mode for AFI and handed to the scope to another colonoscopist who was not aware of the information of HRE. The second colonoscopist who was also selected using a sealed envelope method inserted a colonoscope for $40 \mathrm{~cm}$ and observed the sigmoid colon and rectum under sufficient filling with air. Each colonoscopist separately recorded the colonoscopic findings including the location, color and shape of the detected lesions (Figure 1). Thereafter, both colonoscopists cooperated to insert the scope again and obtain biopsy specimens from all detected lesions. The biopsied specimens were histologically diagnosed by a pathologist with no clinical and endoscopic information according to the Vienna classification [26]. The entire procedural time for each procedure was separately measured and recorded for all the patients. The detected lesions were classified into two groups, elevated type (0IIa) and flat or depressed type (0-IIb or -IIc) according to Paris classification [25]. The detection rate and miss rate of colorectal adenoma by all participants, experienced or less-experienced endoscopists were assessed. The ratio of the cases with adenoma divided by the all cases enrolled was defined as the detection rate. The miss rate was defined as the ratio of all detected adenoma divided by the adenoma as diagnosed by each procedure. The primary goal of this study was to determine the detection ability of AFI in comparison to that of HRE. The second goal was to explore whether the usefulness of AFI for detecting colon lesions was influenced by the morphological features of colon lesions and the experience of the endoscopist. These two secondary outcomes were both exploratory.

\section{Statistical analysis}

To determine the sample size, our preliminary data suggested that the miss rates of HRE and AFI for the detection of colon adenoma were $25.0 \%$ and $4.2 \%$, respectively. When the alpha error was defined as 0.05 (two-sided) and the power as 0.8 , the number of cases required was estimated to be 66 (33 for each group). Twenty-five percent of the enrolled cases were thought to drop out of the study, so the target number of cases was 85 . A total of 88 patients were enrolled and analyzed in this study.

The Wilcoxon signed-rank test was applied for the statistical analysis of the detection and miss rates, and for the procedural time in all participants, because the data were paired and non-parametric. The Mann-Whitney U-test was used to perform the statistical analysis of such data by either experienced or less-experienced endoscopists, because the data were unpaired and non- 

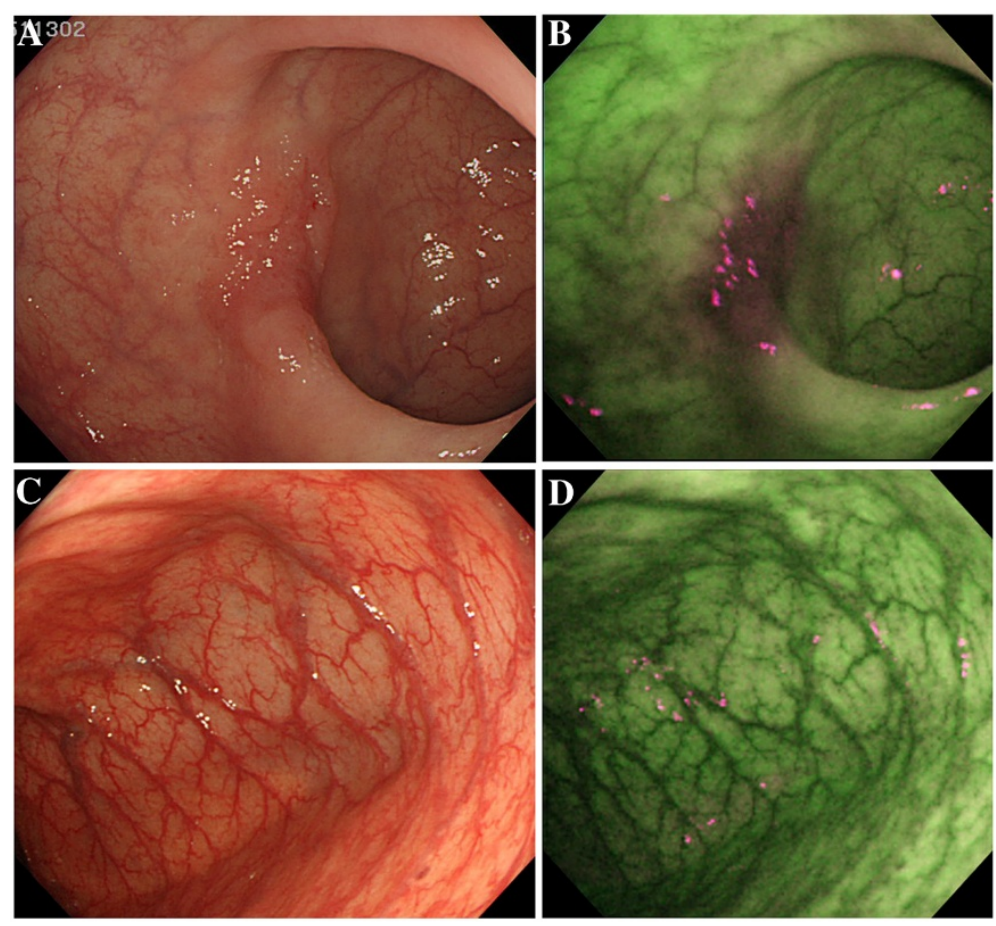

Figure 2 Cases of flat and depressed adenoma and normal mucosa. A faint red area in the sigmoid colon was noted by HRE (A). AFI revealed a strong magenta area at the same site (B). In the normal mucosa, HRE showed no abnormal findings (C) and AFI revealed no magenta area (D).

parametric. A $p$ value $<0.05$ was considered to be statistically significant. For the purposes of the statistical analysis, individual lesions were assumed to constitute statistically independent observations even when more than one lesion was present in a single patient.

\section{Results}

The detection rate of colorectal adenoma and procedural time of HRE and AFI (Table 2).

HRE was performed by experienced endoscopists in 54 of 88 cases and by less-experienced endoscopists in 34 cases. AFI was performed by experienced endoscopists in 55 cases and by less-experienced endoscopists in 33 cases. In 24 of 88 cases, one or more adenomas, which were histologically classified into category 3 or 4.1 according to the Vienna classification [26], were detected by either HRE or AFI. No lesions corresponding to false positive regions, such as normal mucosa or vascular abnormalities, were detected by either HRE or AFI. Whereas HRE detected one or more colorectal adenomas in 16 of 88 cases (18.2\%), AFI detected colorectal adenoma in 23 cases (26.1\%). The detection rate for AFI is therefore significantly higher than that for HRE $(\mathrm{p}<0.05)$. AFI detected 80 -IIb or 0 -IIc adenomas in 88 cases while conventional colonoscopy detected only 3 $(\mathrm{p}<0.05)$. In contrast, no difference was observed between
HRE and AFI regarding the detection rate of 0 -IIa adenomas.

AFI dramatically increased the detection rate of colorectal adenoma (30.3\%) in comparison to that of HRE (7.7\%; $\mathrm{p}<0.05)$ in less-experienced endoscopists. Conversely, the detection rate of HRE in experienced

Table 2 The detection rate of colorectal adenoma w5th HRE and AFI

\begin{tabular}{|c|c|c|c|c|c|}
\hline & Procedures & $\begin{array}{c}\text { S Examined } \\
\text { cases }\end{array}$ & $\begin{array}{l}\text { Cases } \\
\text { with } \\
\text { adenoma } \\
\text { detected }\end{array}$ & $\begin{array}{l}\text { Detection } \\
\text { rates (\%) }\end{array}$ & $\begin{array}{c}p \\
\text { value }\end{array}$ \\
\hline \multirow[t]{2}{*}{ All adenoma } & HRE & 88 & 16 & 18.2 & $p<0.05$ \\
\hline & $\mathrm{AFI}$ & 88 & 23 & 26.1 & \\
\hline \multirow{2}{*}{$\begin{array}{l}\text { Flat and } \\
\text { depressed adenoma }\end{array}$} & HRE & 88 & 3 & 3.4 & $p<0.05$ \\
\hline & AFI & 88 & 8 & 9.1 & \\
\hline \multirow[t]{2}{*}{ Elevated adenoma } & HRE & 88 & 13 & 14.8 & N.S. \\
\hline & AFI & 88 & 15 & 17.0 & \\
\hline \multirow{2}{*}{$\begin{array}{l}\text { Cases examined } \\
\text { by experienced } \\
\text { endoscopists }\end{array}$} & HRE & 54 & 14 & 25.9 & N.S. \\
\hline & $\mathrm{AFI}$ & 55 & 13 & 23.6 & \\
\hline \multirow{2}{*}{$\begin{array}{l}\text { Cases examined } \\
\text { by less } \\
\text { experienced } \\
\text { endoscopists }\end{array}$} & HRE & 34 & 2 & 5.9 & $p<0.05$ \\
\hline & $\mathrm{AFI}$ & 33 & 10 & 30.3 & \\
\hline
\end{tabular}

N.S.; not significant. 
endoscopists (22.6\%) was not significantly different from that of AFI (23.6\%). The procedural time of HRE (144.5 \pm 8.8 seconds) was significantly shorter than that of AFI in all participants $(267.0 \pm 20.8$ seconds; $\mathrm{p}<0.05$; Figure $3 \mathrm{~A})$. This increase in the length of time required to perform the AFI examination was identified for both experienced endoscopists (Figure $3 \mathrm{~B}$ ) as well as lessexperienced endoscopists (Figure 3C).

The miss rate of colorectal adenoma with HRE and AFI (Table 3).

Twenty-nine adenomas were detected by either HRE or AFI in 88 cases. Twenty-one of the 29 adenomas detected from the 88 patients were captured by HRE and 28 were captured by AFI. The miss rate of HRE (27.6\%) was significantly higher than that of AFI (3.4\%; p $<0.05)$. The miss rate of HRE $(50.0 \%)$ was much higher than that of AFI (0\%) in less-experienced endoscopists while no significant deference in the miss rate was seen between HRE (24\%) and AFI (5.3\%) in experienced endoscopists, thus suggesting the efficacy of AFI in detecting colorectal adenoma by less-experienced endoscopists.

\section{Discussion}

The current study demonstrated that AFI improved the detection rate of colorectal adenoma, particularly flat and depressed adenomas, but not for elevated adenomas. An elevated adenoma is easily detected as a reddish and protruding lesion by HRE because HRE can detects abnormalities through capturing the changes of color and shape. However, flat and depressed adenoma is sometimes described just a faint red areas with no elevation, which thus tend to be difficult to detect by HRE. On the other hand, AFI captures the fluorescence mostly emitted from collagen in the submucosal layer and diagnoses the abnormal area through a diminished fluorescence intensity. The dysplastic grade of the lesions is the main factor that affects the fluorescence captured by AFI [27]. The increase in dysplasia appears to facilitate the detection rate of colorectal adenoma by AFI, regardless the shape of the lesion.

A noteworthy finding of the current study is that the efficacy of AFI to detect colorectal adenoma was limited for less-experienced endoscopists. The experienced endoscopists appeared to empirically recognize many of adenomas, even flat and depressed adenoma, with HRE, and thus AFI was not a superior disgnostic modality for experienced endoscopists in detecting colorectal adenoma. The present study revealed that the miss rate with HRE by experienced endoscopists (24.0\%) is relatively lower than that previously reported [22] [26] [28] [29] [30]. This was probably because only highly experienced endoscopists ( $>8000$ standard and $>100$ AFI) were strictly selected as experienced endoscopists in this study. Conversely, it should not be easy for lessexperienced endoscopists to find colorectal adenoma (50.0\%), particularly flat and depressed adenoma, with HRE. Most endoscopists, including less-experienced endoscopists, can immediately utilize AFI because AFI diagnosis is simply based on the color intensity of magenta. This objectivity of AFI probably facilitated the detection rate and reduced the miss rate of colorectal adenoma in less-experienced endoscopists. The clinical value of HRE and AFI is therefore considered to depend on the experience of endoscopists.

Three previous reports have shown controversial results concerning the efficacy of AFI for detecting colorectal adenoma. Matsuda et al. concluded that AFI showed a higher detection rate than did white light endoscopy when using a modified back to back method wherein the authors observed the proximal colon twice, once with white light endoscopy and once with AFI, with both examinations being performed by the same endoscopist [22]. Subsequently, two investigations proposed
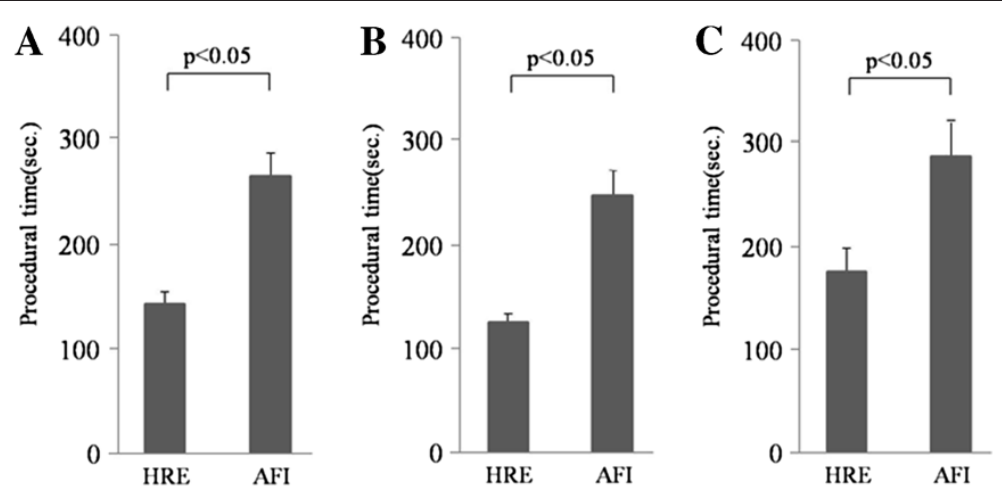

Figure 3 Procedural time of HRE and AFI. The procedural time of HRE (144.5 \pm 8.8 seconds) was significantly shorter than that of AFI in all participants $(267.0 \pm 20.8$ seconds; $p<0.05)(A)$. An increase in the procedural time for the AFI examination was revealed in either experienced endoscopists (B) or less-experienced endoscopists (C). 
Table 3 The miss rate of colorectal adenoma with HRE and AFI

\begin{tabular}{|c|c|c|c|c|c|c|c|}
\hline & lesions & Procedures & Number of lesions & detected & missed & Miss rates (\%) & $\mathrm{p}$ value \\
\hline \multirow[t]{6}{*}{ All participants } & Total & HRE & 88 & & 38 & 43.2 & $p<0.0001$ \\
\hline & & AFI & 88 & & 4 & 4.5 & \\
\hline & Adenoma & HRE & 29 & & 8 & 27.6 & $p<0.05$ \\
\hline & & $\mathrm{AFI}$ & 29 & & 1 & 3.4 & \\
\hline & Hyperplasia & HRE & 59 & & 30 & 50.8 & $p<0.0001$ \\
\hline & & AFI & 59 & & 3 & 5.1 & \\
\hline \multirow[t]{6}{*}{ Experienced endoscopists } & Total & HRE & 60 & & 23 & 38.3 & $p<0.0001$ \\
\hline & & AFI & 62 & & 3 & 4.8 & \\
\hline & Adenoma & HRE & 25 & & 6 & 24.0 & N.S. \\
\hline & & AFI & 19 & & 1 & 5.3 & \\
\hline & Hyperplasia & HRE & 35 & & 17 & 48.6 & $p<0.0001$ \\
\hline & & AFI & 43 & & 2 & 4.7 & \\
\hline \multirow[t]{6}{*}{ Less experienced endoscopists } & Total & HRE & 28 & & 15 & 53.6 & $p<0.0001$ \\
\hline & & AFI & 26 & & 1 & 3.8 & \\
\hline & Adenoma & HRE & 4 & & 2 & 50.0 & $p<0.05$ \\
\hline & & AFI & 10 & & 0 & 0.0 & \\
\hline & Hyperplasia & HRE & 24 & & 13 & 54.2 & $p<0.005$ \\
\hline & & AFI & 16 & & 1 & 6.3 & \\
\hline
\end{tabular}

N.S.; not significant.

the detection rate of AFI and HRE using the back to back method. These studies inspected the entire colon twice during withdrawal: once with AFI and once with HRE by the same endoscopist and found no efficiency of AFI for reducing the adenoma miss-rate in comparison to HRE [23] [24]. These studies possess a potential bias because both endoscopic examinations are performed by the same endoscopist and the second endoscopic diagnosis was therefore influenced by the findings of the first endoscopy. This may explain the controversial results obtained from the two similar studies. Conversely, in the current study, AFI was performed by an endoscopist who was not aware of the information of HRE. This allowed the determination of the efficiency of AFI in the detection of flat and depressed adenoma by less-experienced endoscopists.

Chromoendoscopy can improve the detection of colonic lesions [31-36]. However, chromoendoscopy with magnified observation is time-consuming, operator-dependent and impossible to switch back to the conventional colonoscopy, which may affect the ability to detect mucosal abnormalities in other areas. Narrow band imaging (NBI), a new system in which spectral features are modified by narrowing the bandwidth of spectral transmittance with optical filters and can assess capillary architecture and microvessels just by manipulating a button [37] [38], is also a promising tool to improve the detection rate of colorectal adenoma [28] [39]. Indeed, recent studies have demonstrated adenoma miss- rates for HRE of $40 \%$ to $46 \%$ when a second examination was performed with NBI. This suggests that NBI is superior to HRE when utilized for adenoma detection [28] [29]. Because NBI has a high ability to discriminate colon adenoma from hyperplasia [40] [41], the combination of AFI and NBI can potentially improve the selective detection rate of colon adenoma. Further analysis to compare the efficacy of AFI, NBI or their combination for detecting colon neoplasms is therefore needed to establish the optimal diagnostic modality to perform screening colonoscopy using new advanced imaging systems such as NBI and AFI.

The procedural time to perform AFI $(267.0 \pm 20.8 \mathrm{sec}-$ onds) was significantly longer than that of HRE (144.5 \pm 8.8 seconds). This is a disadvantage of AFI when using it as screening examinations. Whereas AFI can capture the fluorescence emitted from intestinal tissue, the resolution of AFI is still not sufficient. Therefore, endoscopists have to be cautious when performing colonoscopic examinations with AFI, in order not to increase the overall examination time. New advances in endoscopic tools are expected to produce a higher resolution and optimized operation system of AFI, thus leading to a reduction in the time needed to perform the AFI procedures.

Because it is not easy to judge the lesions detected by both HRE and AFI, or either of the two procedures (particularly when multiple lesions are detected), when the entire colon is targeted, this study investigated only the 
recto-sigmoid colon. This is thought to be a limitation of this study. A further analysis covering the entire colon will be warranted to draw conclusions about the overall usefulness of AFI for the detection of colon lesions.

\section{Conclusion}

The current study demonstrated that AFI increased the detection rate and reduced the miss rate of colorectal adenoma, particularly flat and depressed adenomas. However, this advantage of AFI was limited to the lessexperienced endoscopists because experienced endoscopists exhibited a substantially low miss rate of colorectal adenoma with HRE. Further advances in endoscopic instruments will provide an AFI with a high resolution and optimized operation system, thereby preventing the lengthy procedural time which is a disadvantage of AFI.

\section{Competing interests}

We declare that no authors have any financial relationships with commercial entities producing health-care related products and/or services relevant to this article.

\section{Author details}

'Division of Gastroenterology and Hematology/Oncology, Department of Medicine, Asahikawa Medical University, 2-1 Midorigaoka-higashi, Asahikawa, Hokkaido 078-8510, Japan. ${ }^{2}$ Internal Medicine, Kotoni Royal Hospital, 2-Nishi1-1-1, Hachiken, Nishi-ku, Sapporo, Hokkaido 063-0842, Japan. ${ }^{3}$ Internal Medicine, Kushiro Medical Association Hospital, 4-30 Nusamai-cho, Kushiro, Hokkaido 085-0836, Japan. ${ }^{4}$ Division of Upper Gastroenteroelogy, Department of Internal Medicine, Hyogo College of Medicine, 1-1 Mukogawa-cho, Nishinomiya, Hyogo 663-8501, Japan. ${ }^{5}$ Digestive Disease Center, Asahikawa City Hospital, 1-1-65 Kinsei-cho, Asahikawa, Hokkaido 070-8610, Japan.

\section{Author's contributions}

K.M. and M.F. provided major input into the conceptual development of the studies, wrote the manuscript and supervised all investigations. R.S., J.W., Y.N., T.N., N.U., S.K., K.I., Y.I. and H.T. performed the endoscopic examinations. Y.I. assessed the histological findings. S.M., C.I., T.I. and K.O. managed and treated the enrolled patients and collected and analyzed the data. Y.M., Y.S. and Y.K. helped design studies, interpret the data, and prepare/review the manuscript. All authors read and approved the final manuscript.

Received: 12 October 2011 Accepted: 22 June 2012

Published: 22 June 2012

\section{References}

1. Potter JD: Colorectal cancer: molecules and populations. J Nat/ Cancer Inst 1999, 91:916-932.

2. Fearon $E R$, Vogelstein B: A genetic model for colorectal tumorigenesis. Cell 1990, 61:759-767.

3. Lengauer C, Kinzler K, Vogelstein B: Genetic instabilities in human cancers. Nature 1998, 396:643-649.

4. Winawer SJ, Zauber AG, Ho MN, O'Brien MJ, Gottlieb LS, Sternberg SS, Waye JD, Schapiro M, Bond JH, Panish JF, Ackroyd F, Shike M, Kurtz RC, HornsbyLewis L, Gerdes H, Stewart ET, National Polyp Study Workgroup: Prevention of Colorectal Cancer by Colonoscopic Polypectomy. N Eng J Med 1993, 329:1977-1981.

5. Robertson DJ, Greenberg ER, Beach M, Sandler RS, Ahnen D, Haile RW, Burke CA, Snover DC, Bresalier RS, McKeown-Eyssen G, Mandel JS, Bond JH, Van Stolk RU, Summers RW, Rothstein R, Church TR, Cole BF, Byers T, Mott L, Baron JA: Colorectal cancer in patients under close colonoscopic surveillance. Gastroenterology 2005, 129:34-41.

6. van Rijn JC, Reitsma JB, Stoker J, Bossuyt PM, van Deventer SJ, Dekker E: Polyp miss rate determined by tandem colonoscopy: a systematic review. Am J Gastroenterol 2006, 101:343-350.
7. Fujii T, Rembacken BJ, Dixon MF, Yoshida S, Axon AT: Flat adenomas in the United Kingdom: are treatable cancers being missed? Endoscopy 1998, 30:437-443

8. Rembacken BJ, Fujii T, Cairns A, Dixon MF, Yoshida S, Chalmers DM, Axon AT: Flat and depressed colonic neoplasms: a prospective study of 1000 colonoscopies in the UK. Lancet 2000, 355:1211-1214.

9. Saitoh Y, Waxman I, West AB, Popnikolov NK, Gatalica Z, Watari J, Obara T, Kohgo Y, Pasricha PJ: Prevalence and distinctive biologic features of flat colorectal adenomas in a North American population. Gastroenterology 2001, 120:1657-1665.

10. Tsuda S, Veress B, Tóth E, Fork FT: Flat and depressed colorectal tumours in a southern Swedish population: a prospective chromoendoscopic and histopathological study. Gut 2002, 51:550-555.

11. Takehana S, Kaneko M, Mizuno H: Endoscopic Diagnostic System Using Autofluorescence. Diagnostic and Therapeutic Endoscopy 1999, 5:59-63.

12. Namihisa A, Miwa H, Watanabe H, Kobayashi O, Ogihara T, Sato N: A new technique: light-induced fluorescence endoscopy in combination with pharmacoendoscopy. Gastrointest Endosc 2001, 53:343-348.

13. Georgakoudi I, Jacobson BC, Van Dam J, Backman V, Wallace MB, Müller MG, Zhang Q, Badizadegan K, Sun D, Thomas GA, Perelman LT, Feld MS: Fluorescence, reflectance, and light-scattering spectroscopy for evaluating dysplasia in patients with Barrett's esophagus. Gastroenerology 2001, 120:1620-1629.

14. Borovicka J, Fischer J, Neuweiler J, Netzer P, Gschossmann J, Ehmann T, Bauerfeind P, Dorta G, Zürcher U, Binek J, Meyenberger C: Autofluorescnce endoscopy in surveillance of Barrett's esophagus. A multicenter randomized trial on diagnostic efficacy. Endoscopy 2006, 38:867-872.

15. Kara MA, Bergman JJGH: Autofluorescence imaging and narrow-band imaging for the detection of early neoplasia inpatients with Barrett's esophagus. Endoscopy 2006, 38:627-631.

16. Uedo $N$, lishi H, Tatsuta M, Yamada T, Ogiyama H, Imanaka K, Sugimoto $N$, Higashino K, Ishihara R, Narahara H, Ishiguro S: A novel videoendoscopy system by using autofluorescence and reflectance imaging for diagnosis of esophagogastric cancers. Gastrointest Endosc 2005, 62:521-528.

17. Messmann H, Endlicher E, Freunek G, Rümmele P, Schölmerich J, Knüchel R: Fluorescence endoscopy for the detection of lowand high grade dysplasia in ulcerative colitis using systemic or local 5-aminolaevulinic acid sensitization. Gut 2003, 52:1003-1007.

18. Matsumoto T, Moriyama T, Yao T, Mibu R, lida M: Autofluorescence imaging colonoscopy for the diagnosis of dysplasia in ulcerative colitis. Inflamm Bowel Dis 2007, 13:640-641.

19. van den Broek FJ, Fockens P, van Eeden S, Reitsma JB, Hardwick JC, Stokkers PC, Dekker E: Endoscopic tri-modal imaging for surveillance in ulcerative colitis: randomised comparison of high-resolution endoscopy and autofluorescence imaging for neoplasia detection; and evaluation of narrow-band imaging for classification of lesions. Gut 2008, 57:1083-1089.

20. Ueno N, Fujiya M, Moriichi K, Ikuta K, Nata T, Konno Y, Ishikawa C, Inaba Y, Ito T, Sato R, Okamoto K, Tanabe H, Maemoto A, Sato K, Watari J, Ashida T, Saitoh Y, Kohgo Y: Endosopic Autofluorescence Imaging is Useful for the Differential Diagnosis of Intestinal Lymphomas Resembling Lymphoid Heyperplasia. J Clin Gastroenterol 2011, 45:507-513.

21. Fujiya M, Saitoh Y, Watari J, Moriichi K, Kohgo Y: Auto-Fluorescence Imaging is useful to assess the activity of ulcerative colitis. Dig Endosc 2007, 19:145-149.

22. Matsuda T, Saito Y, Fu Kl, Uraoka T, Kobayashi N, Nakajima T, Ikehara H, Mashimo Y, Shimoda T, Murakami Y, Parra-Blanco A, Fujimori T, Saito D: Does autofluorescence imaging videoendoscopy system improve the colonoscopic polyp detection rate?-a pilot study. Am J Gastroenterol 2008, 103:1926-1932.

23. van den Broek FJ, Fockens P, Van Eeden S, Kara MA, Hardwick JC, Reitsma $J B$, Dekker E: Clinical evaluation of endoscopic trimodal imaging for the detection and differentiation of colonic polyps. Clin Gastroenterol Hepatol 2009, 7:288-295.

24. Rotondano G, Bianco MA, Sansone S, Prisco A, Meucci C, Garofano ML, Cipolletta L: Trimodal endoscopic imaging for the detection and differentiation of colorectal adenomas: a prospective single-centre clinical evaluation. Int J Colorectal Dis 2012, 27:331-336.

25. Participants in the Paris Workshop. The Paris endoscopic classification of superficial neoplastic lesions: esophagus, stomach, and colon: November 30 to December 1, 2002. Gastrointest Endosc 2003, 58:3-43. 
26. Schlemper RJ, Riddell RH, Kato Y, Borchard F, Cooper HS, Dawsey SM, Dixon MF, Fenoglio-Preiser CM, Fléjou JF, Geboes K, Hattori T, Hirota T, Itabashi M, Iwafuchi M, Iwashita A, Kim Yl, Kirchner T, Klimpfinger M, Koike M, Lauwers GY, Lewin KJ, Oberhuber G, Offner F, Price AB, Rubio CA, Shimizu M, Shimoda T, Sipponen P, Solcia E, Stolte M, Watanabe H, Yamabe H: The Vienna classification of gastrointestinal epithelial neoplasia. Gut 2000, 47:251-255

27. Moriichi K, Fujiya M, Sato R, Nata T, Nomura $Y$, Ueno N, Ishikawa C, Inaba $Y$, Ito T, Okamoto K, Tanabe H, Mizukami Y, Watari J, Saitoh Y, Kohgo Y: Autofluorescence imaging and the quantitative intensity of fluorescence for evaluating the dysplastic grade of colonic neoplasms. Int I Colorectal Dis 2011, 27:325-330.

28. Rastogi A, Bansal A, Wani S, Callahan P, McGregor DH, Cherian R, Sharma P: Narrow-band imaging colonoscopy-a pilot feasibility study for the detection of polyps and correlation of surface patterns with polyp histologic diagnosis. Gastrointest Endosc 2008, 67:280-286.

29. East JE, Suzuki N, Stavrinidis M, Guenther T, Thomas HJ, Saunders BP: Narrow band imaging for colonoscopic surveillance in hereditary nonpolyposis colorectal cancer. Gut 2008, 57:65-70.

30. Heresbach D, Barrioz T, Lapalus MG, Coumaros D, Bauret P, Potier P, Sautereau D, Boustière C, Grimaud JC, Barthélémy C, Sée J, Serraj I, D'Halluin PN, Branger B, Ponchon T: Miss rate for colorectal neoplastic polyps: a prospective multicenter study of back-to-back video colonoscopies. Endoscopy 2008, 40:284-290.

31. Brooker JC, Saunders BP, Shah SG, Thapar CJ, Thomas HJ, Atkin WS, Cardwell CR: Williams CB; Total colonic dye-spray increases the detection of diminutive adenomas during routine colonoscopy: a randomized controlled trial. Gastrointest Endosc 2002, 56:333-338.

32. Hurlstone DP, Cross SS, Slater R, Sanders DS, Brown S: Detecting diminutive colorectal lesions at colonoscopy: a randomised controlled trial of pancolonic versus targeted chromoscopy. Gut 2004, 53:376-380.

33. Lapalus MG, Helbert T, Napoleon B, Rey JF, Houcke P: Ponchon T; Société Française d'Endoscopie Digestive: Does chromoendoscopy with structure enhancement improve the colonoscopic adenoma detection rate?. Endoscopy 2006, 38:444-448.

34. Le Rhun M, Coron E, Parlier D, Nguyen JM, Canard JM, Alamdari A, Sautereau D, Chaussade S, Galmiche JP: High resolution colonoscopy with chromoscopy versus standard colonoscopy for the detection of colonic neoplasia: a randomized study. Clin Gastroenterol Hepatol 2006, 4:349-354.

35. Kato S, Fujii T, Koba I, Sano Y, Fu Kl, Parra-Blanco A, Tajiri H, Yoshida S, Rembacken B: Assessment of colorectal lesions using magnifying colonoscopy and mucosal dye spraying: can significant lesions be distinguished? Endoscopy 2001, 33:306-310.

36. Fu Kl, Sano Y, Kato S, Fujii T, Nagashima F, Yoshino T, Okuno T, Yoshida S, Fujimori T: Chromoendoscopy using indigo carmine dye spraying with magnifying observation is the most reliable method for differential diagnosis between non-neoplastic and neoplastic colorectal lesions: a prospective study. Endoscopy 2004, 36:1089-1093.

37. Gono K, Yamazaki K, Doguchi N, Nonami T, Obi T, Yamaguchi M, Ohyama N, Machida H, Sano Y, Yoshida S, Hamamoto Y, Endo T: Endoscopic observation of tissue by narrow band illumination. Opt Rev 2003, 10:211-215.

38. Gono K, Obi T, Yamaguchi M, Ohyama N, Machida H, Sano Y, Yoshida S, Hamamoto $Y$, Endo T: Appearance of enhanced tissue features in narrowband endoscopic imaging. J Biomed Opt 2004, 9:568-577.

39. Inoue T, Murano M, Murano N, Kuramoto T, Kawakami K, Abe Y, Morita E, Toshina K, Hoshiro H, Egashira Y, Umegaki E, Higuchi K: Comparative study of conventional colonoscopy and pan-colonic narrow-band imaging system in the detection of neoplastic colonic polyps: a randomized, controlled trial. J Gastroenterol 2008, 43:45-50.

40. van den Broek FJ, van Soest EJ, Naber AH, van Oijen AH, Mallant-Hent RCh, Böhmer CJ, Scholten P, Stokkers PC, Marsman WA, Mathus-Vliegen EM, Curvers WL, Bergman JJ, van Eeden S, Hardwick JC, Fockens P, Reitsma JB, Dekker $\mathrm{E}$ : Combining autofluorescence imaging and narrow-band imaging for the differentiation of adenomas from non-neoplastic colonic polyps among experienced and non-experienced endoscopists. Am J Gastroenterol 2009, 104:1498-1507.
41. Sato R, Fujiya M, Watari J, Ueno N, Moriichi K, Kashima S, Maeda S, Ando K, Kawabata H, Sugiyama R, Nomura Y, Nata T, Itabashi K, Inaba Y, Okamoto K, Mizukami Y, Saitoh Y, Kohgo Y: The diagnostic accuracy of high-resolution endoscopy, autofluorescence imaging and narrow-band imaging for differentially diagnosing colon adenoma. Endoscopy 2011, 43:862-868.

doi:10.1186/1471-230X-12-75

Cite this article as: Moriichi et al.: Back-to-Back Comparison of AutoFluorescence Imaging (AFI) Versus High Resolution White Light Colonoscopy for Adenoma Detection. BMC Gastroenterology 2012 12:75.

\section{Submit your next manuscript to BioMed Central and take full advantage of:}

- Convenient online submission

- Thorough peer review

- No space constraints or color figure charges

- Immediate publication on acceptance

- Inclusion in PubMed, CAS, Scopus and Google Scholar

- Research which is freely available for redistribution

Submit your manuscript at www.biomedcentral.com/submit
C) Biomed Central 